Volume 7

Issue 2 Spring 2004

Article 3

November 2015

\title{
Achieving Equality: Healthcare Governance in Transition
}

Louise G. Trubek

Maya Das

Follow this and additional works at: https://via.library.depaul.edu/jhcl

\section{Recommended Citation}

Louise G. Trubek \& Maya Das, Achieving Equality: Healthcare Governance in Transition, 7 DePaul J. Health Care L. 245 (2004)

Available at: https://via.library.depaul.edu/jhcl/vol7/iss2/3

This Article is brought to you for free and open access by the College of Law at Digital Commons@DePaul. It has been accepted for inclusion in DePaul Journal of Health Care Law by an authorized editor of Digital Commons@DePaul. For more information, please contact digitalservices@depaul.edu. 


\title{
ACHIEVING EQUALITY: HEALTHCARE GOVERNANCE IN TRANSITION*
}

\author{
Louise G. Trubek"* \\ \& Maya Das **
}

\section{INTRODUCTION}

Healthcare is not immune to the deeply rooted inequalities in American society. To this day, racial and ethnic differences exist in the quality and outcomes of healthcare that cannot be attributed to socioeconomic or other healthcare access factors. Lawyers committed to social justice have long dedicated energy and attention to these continued disparities. As a lawyer litigating against segregation in healthcare facilities noted in 1966, "The treatment accorded Negroes by Southern medical facilities . . . reflects a striking contradiction between law and practice." ${ }^{\prime}$ Past efforts to achieve equality in healthcare through civil rights litigation, education and local organizing have been effective to a degree, but have lost their influence in the current healthcare environment. In a renewed effort to achieve racial and ethnic equality in healthcare, some advocates are turning to quality as an indirect route to attaining this goal. The quality approach requires changing the traditional healthcare framework by incorporating new methods for achieving quality into every level of the system, including the patient level, the clinical level, the healthcare organization level and the governance level. ${ }^{2}$

Drastically changing the framework of the healthcare system is not easy. There are barriers in the traditional framework that work against

Copyright 2003, Reprinted with the permission of the American Society of Law, Medicine \& Ethics. All rights reserved.

"Clinical Professor of Law, University of Wisconsin

"*M.D./J.D. anticipated 2005, University of Wisconsin. The authors extend their deepest appreciation to Jeanne Cavanaugh for her research and editing. The authors would also like to thank the many people interviewed in connection with this Article. Special thanks to our friend and colleague Eva Cohen.

'Michael Meltsner, Equality and Health, 115 U. PA. L. Rev. 22, 22 (1966)

'Donald M. Berwick, A User's Manual for the IOM's 'Quality Chasm' Report, 21 Health AFF. 80, 84-88 (2002). 
innovation. To overcome these barriers, some organizations have implemented programs that realign relationships among the levels of government, increase use of networks and link public agencies and private organizations. Two exemplary projects that have succeeded in overcoming the barriers to change are the Health Disparities Collaboratives and quality-based programs instituted within certain physician-led managed care systems. Their stories demonstrate a "fit" between the provision of high quality equitable care and the creation of a revised governance framework that allows these new quality approaches to take hold.

This Article begins with a discussion of traditional approaches to eliminating racial disparities in healthcare and lays out their limitations. It then describes two exemplary projects within healthcare institutions that are reducing racial and ethnic disparities by using a disease management approach. The Article proposes how these exemplary projects can be viewed as a model for embedding quality into the healthcare system. Finally, the Article lays out a timely opportunity for actors in the healthcare system to buy into the quality-based framework and to encourage its diffusion.

\section{A SHORT HISTORY OF PAST EFFORTS TO ELIMINATE RACIAL DISPARITIES}

Historically, the U.S. healthcare system has demonstrated an inability to provide care equitably to all of its patients. ${ }^{3}$ For years, lawyers, healthcare professionals and minority communities have worked to overcome these painful disparities through a variety of approaches. ${ }^{4}$ However, the success of these approaches has been limited as demonstrated by the recent flurry of studies indicating the continued existence of racial disparities in healthcare outcomes. ${ }^{5}$ The Institute of Medicine reports:

${ }^{3}$ See M. Gregg Bloche, Race and Discretion in American Medicine, 1 Yale J. HeAlTH POL'Y L. \& ETHICS 95 (2001); Rene Bowser, Racial Bias in Medical Treatment, 105 DicK. L. REV. 365 (2001); Vernellia R. Randall, Slavery, Segregation and Racism: Trusting the American Health Care System Ain't Always Easy! An African American Perspective on Bioethics, 15 ST. LouIs U. PuB. L. REv. 191 (1996).

"The Institute of Medicine has defined "disparities in healthcare" as "racial or ethnic differences in the quality of healthcare that are not due to access-related factors or clinical needs, preferences, and appropriateness of intervention." INST. OF MED., UNEQUAL TREATMENT, 4-5 (2003).

${ }^{5}$ See Bowser, supra note 3. 
The health gap between minority and non-minority Americans has persisted, and in some cases, has increased in recent years. African-American men, for example, experienced an average life expectancy of 61 years in 1960, compared with 67 years for their white male peers; in 1996, this gap increased to 8 years, as white males enjoyed an average life expectancy of 74 years, relative to 66 years for African-American males. American-Indian men in some regions of the country can expect to live only into their mid-fifties. Further, African-American and American-Indian infant mortality rates remain approximately 2.5 and 1.5 times higher, respectively, than rates for whites. ${ }^{6}$

In 1999, public awareness of disparities in clinical decisionmaking was piqued by a study indicating racial disparities in cardiovascular treatment. ${ }^{7}$ The results of this study shifted attention toward the decision-making of healthcare providers and the appropriate use of race and ethnicity in medical evaluations. ${ }^{8}$ Recently, the Healthy People 2010 report and the Institute of Medicine's report on racial and ethnic disparities have indicated a continued awareness of racial disparities in healthcare. ${ }^{9}$ Documentation of disparities has indicated that, although racial and ethnic disparities in healthcare are often equated with socioeconomic disadvantage, controlling for variations in insurance coverage does not eliminate the differences in treatment between majority and minority populations. ${ }^{10}$ Indeed, minority patients often receive less aggressive treatment, experience lower rates of surgical treatment and receive fewer referrals to specialists than white

${ }^{6}$ INST. OF MED., supra note 4, at 35

'Kevin A. Schulman et al., The Effect of Race and Sex on Physicians' Recommendations for Cardiac Catheterization, 340 NEw ENG. J. MED. 618, 618-26 (1999). The New England Journal of Medicine eventually retracted portions of the article Gregory D. Curfman \& Jerome P. Kassirer, Race, Sex and Physicians' Referrals for Cardiac Catheterization--The Editors Reply, 341 NEw ENG. J. MED. 285, 287 (1999), but it remained influential.

${ }^{8}$ See Bloche, supra note 3, at 95-96.

${ }^{9}$ Office of Disease Prevention \& Health Promotion, U.S. Dep't of Health \& Human Serv. (HHS), Healthy PeOPle 2010 (2000), at http://www.healthypeople.gov/document; INST. OF MED., supra note 4.

${ }^{10}$ See Marian E. Gornick et al., Effects of Race and Income on Mortality and Use of Services Among Medicare Beneficiaries, 335 NEw EnG. J. MED. 791, 793-97 (1996) [hereinafter Gornick, Effects of Race]; See also Marian E. Gornick et al., Understanding Disparities in the Use of Medicare Services, 1 YALE J. Health PoL'y L. \& ETHICS 133 (2001) [hereinafter Gornick, Understanding Disparities] (discussing disparities in the use of preventive services by minority and socioeconomically disadvantaged Medicare patients). 
patients." These differences are associated with higher rates of morbidity and mortality in minority populations, and are significantly marked when dealing with chronic illnesses. ${ }^{12}$

Traditionally, three routes have been pursued to eliminate racial disparities in healthcare: the civil rights litigation approach, the education and multicultural approach, and the local organizing approach.

\section{The Civil Rights Litigation Approach}

The civil rights litigation approach made dramatic strides in the 1960s, primarily due to the efforts of the NAACP Legal Defense \& Educational Fund (Legal Defense Fund). ${ }^{13}$ Though health was not a top priority, the Legal Defense Fund and other civil rights organizations made some progress in this area. ${ }^{14}$ For example, the Legal Defense Fund won a major victory in 1964, when the U.S. Supreme Court refused to review the Fourth Circuit's ruling that the "separate but equal" provision of the Hill-Burton Act of 1946 was unconstitutional as applied to hospitals and other healthcare facilities. ${ }^{15}$

The success of litigation, coupled with the societal and political will of the times, led to the passage of Title VI of the Civil Rights Act of $1964 .^{16}$ Title VI prohibits federally funded programs or activities from discriminating on the basis of race, color or national origin. ${ }^{17}$ Federal agencies are responsible for enforcement of this law. For issues involving discrimination in healthcare, the Office for Civil Rights (OCR) in the Department of Health, Education, and Welfare (now the Department of Health and Human Services, or HHS) was charged with this task. ${ }^{18}$ Despite the government's efforts to eliminate discrimination with Title VI, private litigation persisted through the 1960s and into the 1970s because of perceived unresponsiveness. ${ }^{19}$ The Legal Defense

\footnotetext{
"Bowser, supra note 3; See also Gornick, Understanding Disparities, supra note 10, at 137-39 (comparing utilization patterns of black and white Medicare patients).

${ }^{12}$ See Gornick, Effects of Race, supra note 10, at 793-94.

${ }^{13}$ See, e.g., Brown v. Board of Educ., 347 U.S. 483, 493 (1954) (holding that segregation of schools based solely on race violates the Fourteenth Amendment of the Constitution).

${ }^{14}$ Marianne Engelman Lado, Unfinished Agenda: The Need for Civil Rights Litigation to Address Race Discrimination and Inequalities in Health Care Delivery, 6 TEX. F. ON C.L. \& C.R. 1, 16 (2001).

${ }^{15}$ Simkins v. Moses H. Cone Mem'l Hosp., 323 F.2d 959 (4th Cir. 1963).

${ }^{16}$ Title VI of the Civil Rights Act of 1964, 42 U.S.C. $\S 2000 d$ (2000).

${ }^{17} I d$.

${ }^{18} I d$. $\S 2000 \mathrm{~d}-1$. Title VI implementing regulations for HHS can be found at 45 CFR $\S$ $80(2001)$.

${ }^{19}$ See Sidney D. Watson, Race, Ethnicity and Quality of Care: Inequalities and Incentives, 27 AM. J.L. \& MED. 203, 214 (2001) (discussing the impact of Medicare and Medicaid programs as an important federal financial presence that served as an incentive to desegregate hospital and physician practices).
} 
Fund, for example, filed suit on behalf of minority doctors, dentists, and nurses who were denied privileges at publicly supported facilities or excluded from professional societies, initiated cases for the desegregation of Southern hospitals and other health facilities, and challenged discriminatory admission and treatment practices. ${ }^{20}$ These suits were successful and were crucial for the desegregation of healthcare facilities.

Over the past twenty years, however, the civil rights litigation approach has been unable to further impact health disparities due to a lack of success in the courts, a dearth of lawyers willing to take cases and weak outcomes even when litigation has been successful. ${ }^{21}$ During the 1970s, the Legal Defense Fund began bringing a series of disparate impact Title VI cases to prevent the closure of inner city health facilities that served predominantly minority populations. ${ }^{22}$ However, its efforts were stymied by a Second Circuit affirmation of a district court's decision, which essentially increased the burden for showing harm in disparate impact cases. ${ }^{23}$ Proponents of the litigation approach have continued to bring suits, but with little success. ${ }^{24}$ The Supreme Court's recent holding in Alexander v. Sandoval, stating that there is no private right of action to enforce disparate impact regulations promulgated under Title VI, further undermines the civil rights litigation approach. ${ }^{25}$ The lack of success has led to discouragement among those who worked on Title VI cases in the healthcare context. While organizations such as the National Health Law Program and the New York Public Interest Law Firm continue to work in this area, the Legal Defense Fund no longer pursues healthcare related cases. ${ }^{26}$

At the federal agency level, OCR has been unable to fulfill its responsibility to eliminate racial disparities and discrimination in the healthcare system. ${ }^{27}$ OCR has neither established the requirements needed to show harm or the appropriate standards for assessing claims

\footnotetext{
${ }^{20} \mathrm{Lado}$, supra note 14 , at $19-20$.

${ }^{21}$ See Watson, supra note 19; Lado, supra note 14, at 27 (2001); Bryan v. Koch, 627 F.2d 612 (2d Cir. 1980); NAACP v. Wilmington Med. Ctr., Inc., 657 F.2d 1322 (3d Cir. 1981).

${ }^{22}$ Lado, supra note 14 , at $21-22$.

${ }^{23}$ Bryan v. Koch, 492 F. Supp. 212 (S.D.N.Y. 1980), affd, 627 F.2d 612 (2d Cir. 1980). The district court found that "any inconveniences . . . in this case do not rise to the level of harm necessary to enlist the equitable powers of this court." Id. at 237.

${ }^{24}$ Lado, supra note 14, at 22-26; Telephone Interview with Marianne Engelman Lado, General Counsel, New York Lawyers for Public Interest (Aug. 9, 2002).

${ }^{25} 532$ U.S. at 289.

${ }^{26}$ Telephone Interview with Marianna Engelman Lado, supra note 24

${ }^{27} \mathrm{See} 1$ U.S. COMMISSION ON CIVIL RIGHTS (USCCR), THE HEALTH CARE CHALLENGE: ACKNOWLEDGING DISPARITY, CONFRONTING DISCRIMINATION, AND ENSURING EQUALITY 189-90 (1999); 2 id. at 76-88, 273-78, 298-307, 321-23, 34145 .
} 
in health-related disparate impact cases nor analyzed relevant statutory and case law that affects enforcement activities. ${ }^{28}$ In fact, OCR has hardly developed its Title VI enforcement program since $1980 .^{29}$ Its regulations and policy guidance on the issue have not been revised since before the division of the former Department of Health, Education, and Welfare. ${ }^{30}$

Furthermore, what minimal action OCR has taken has been reactive, not proactive. OCR has consistently lacked the funding and staff for conducting systematic compliance reviews and, thus, relies on the filing of complaints. ${ }^{31}$ The complaint approach used by OCR, however, has two "gatekeeping" problems with regard to racial and ethnic disparities: (1) the filing process and the lack of expertise in this area results in few complaints being interpreted as related to disparities and (2) the advocacy community has not been focused on this issue. ${ }^{32}$ Even after a complaint enters the system, OCR's investigative processes are inadequate and slow in finding violations, resulting in inordinate lengths of time for case resolution and a finding of compliance in most race-related cases. ${ }^{33}$

\section{The Education and Multicultural Approach}

The education and multicultural approach is based on the premise that increasing the number of underrepresented minority physicians can reduce health disparities. Since the 1970 s and 1980 s, when the enrollment numbers of minorities in medical school increased dramatically, studies have been conducted to determine the impact of the increased number of minority physicians on healthcare delivery. Certain trends have been found: a larger proportion of minority physicians practice in metropolitan areas, have larger numbers of minority patients and practice in a primary care specialty. ${ }^{34}$ Furthermore, a 1996 study found that, in general, physicians tend to practice in areas where residents of their own race/ethnicity predominate. ${ }^{35}$

\footnotetext{
${ }^{28} 2$ id. at $298,301$.

${ }^{29} \mathrm{Id}$. at 77 .

${ }^{30} \mathrm{Id}$.

${ }^{31}$ Id. at $274,322$.

${ }^{32}$ Id. at $278,321-22$.

${ }^{33} \mathrm{Id}$. at 341 .

${ }^{34}$ Raynard Kington et al., Increasing Racial and Ethnic Diversity Among Physicians: An Intervention to Address Health Disparities, in IOM, THE RIGHT THING TO DO, THE SMART THING TO DO: ENHANCING DIVERSITY IN HEALTH PROFESSIONS-SUMMARY OF THE SYMPOSIUM ON DIVERSITY IN HEALTH PROFESSIONS IN HONOR OF HERBERT W. NICKENS, M.D. 64-75 (2001).

${ }^{35}$ Komaromy et al., The Role of Black and Hispanic Physicians in Providing Health Care for Underserved Populations, 334 NEW ENG. J. MED. 1305 (1996).
} 
Efforts to increase minority enrollment in medical school, however, have been hindered by the legal limits placed on affirmative action programs. $^{36}$ A number of public and private institutions of higher education have removed race or ethnicity as a factor in consideration for admissions, but many continue to actively and aggressively recruit minority students. The American Association of Medical Colleges (AAMC) has created programs to encourage minority application and eventual acceptance into medical school. ${ }^{37}$ Nonetheless, the proportion of underrepresented minority students in medical school is declining. ${ }^{38}$

Proponents of the education and multicultural approach believe that increasing the number of minority healthcare professionals will improve cross-cultural competence and patient-physician communication. Study results, however, have been ambivalent regarding these outcomes. ${ }^{39}$ Many medical schools have struggled with implementing cross-cultural competence training, partially due to the fear of perpetuating stereotypes and misconceptions rather than dispelling them. $^{40}$ Furthermore, the variability in the training programs has called into question their value.

\section{The Local Organizing Approach}

Attempts to address healthcare disparities have also been made on a local level. Some organizations have successfully implemented programs to improve access to preventive and primary care for disadvantaged populations in their communities. Programs affiliated

${ }^{36}$ See, e.g., Regents of Univ. of California v. Bakke, 438 U.S. 265 (1978); Hopwood v. Texas, 236 F.3d 256 (2000); see also CAL. CONST., art. I, \& 31 (stating that California will not discriminate or grant preferential treatment on the basis of "race, sex, color, ethnicity, or national origin, gender-based qualifications in public employment, education, or contracting").

${ }^{37}$ The AAMC is currently in the process of re-defining underrepresented minority for medical school application purposes. Information on the AAMC programs for minority medical school applicants and students can be found at the Am. Ass'n of Med. Coll. website, at http://www.aamc.org (last visited Mar. 10, 2003).

${ }^{38}$ Medical school applications overall have been declining for the past six years. The decrease in the proportion of underrepresented minority students has been even more dramatic. Data tables for characteristics of medical school applicants and matriculants, including by race/ethnicity, can be found at http:/www.aamc.org/data/facts/start.htm (providing tables with information about, among other things, the gender, race, ethnicity and geographic origin of medical school applicants between the years of 1992 and 2002).

${ }^{39}$ Kington et al., supra note 34 , at 83 .

${ }^{40} \mathrm{Cross}$-cultural competence training in medical schools is an area that has received much attention in the past couple of years. The Health Care Fairness Act of 2000 now provides federal grants and awards for the training and education of health professionals for the provision of culturally competent healthcare. 42 U.S.C. $\$ 293 e(2000)$. 
with medical schools, often through family medicine departments, have also encouraged service to local, disadvantaged populations. ${ }^{41}$

Despite some promising efforts, the success of local organizing has been limited and variable. Many organizations operate within narrow geographic boundaries and do not have the vision for expansion. Moreover, links between groups are often minimal. Local organizations often work independently of each other and do not have regional or national support. This leads to fragmented programs and large variation in the availability of services in a particular community. Local organizations also suffer from inadequate resources and those that rely on grant money must sometimes shift their focus to meet funding requirements. This can lead to a lack of programmatic continuity and can reduce the potential positive impact of the program.

\section{THE EMERGING MODEL: INSTITUTIONS THAT DELIVER QUALITY AND EQUITABLE CARE}

Although initially successful, the effectiveness of past approaches to achieving equity in healthcare has stalled. ${ }^{42}$ In response to the persistence of health disparities, some providers are adopting a qualitybased approach to the provision of healthcare as an indirect route to achieving equity. These providers are utilizing a set of organizational models known as "disease management" to improve the overall quality of care for all patients and to bring the quality of care provided to minority patients into balance. Disease management programs have a substantially greater positive effect on the health outcomes of racial and ethnic minorities because these programs focus on chronic illnesses such as diabetes, asthma and cardiovascular disease, which have traditionally effected minorities disproportionately. ${ }^{43}$ By improving the quality of care for all patients suffering from these chronic diseases, disease management programs can improve the quality of care for racial and ethnic minority patients.

${ }^{41}$ See, e.g., Joseph C. Gerber \& David L. Stewart, Prevention and Control of Hypertension and Diabetes in an Underserved Population Through Community Outreach and Disease Management: $A$ Plan of Action, 9 J. ASS'N ACADEMIC MINORITY PHYSICIANS 48,48 (1998) (describing a program with support from Department of Family Medicine at the University of Maryland School of Medicine and other organizations); Univ. of Wisconsin Med. Sch., Welcome to Medic (2001), at http://www.fammed.wisc.edu/medic (describing their program for providing primary care services to the underserved).

${ }^{42}$ See Bowser, supra note 3.

${ }^{43} \mathrm{See}$ id. 
Disease Management Programs: Using Quality to Achieve Equity Management programs grew out of the cost control and quality improvement mechanisms that emerged during the managed care revolution. In the 1990 s, quality reformers pushed for an increased focus on preventive medicine and primary care as methods for reducing overall healthcare costs. As a result, organizational models were developed that centered on coordinating the delivery of appropriate, high-quality medical care for a specific condition during the life of a patient. These models are known as disease management programs.

There are six key components of disease management programs: (1) evidence-based medicine guidelines, (2) population identification processes, (3) patient self-management education, (4) collaborative practice models, (5) process and outcomes measurement, evaluation and management, and (6) routine reporting/feedback loop. ${ }^{44}$ Although each of these components individually helps to achieve quality and, indirectly, equity in healthcare, their impact is much more significant when combined. The extent to which a specific disease management program incorporates each component varies, but the most successful programs fully incorporate all six components.

Disease management programs are able to improve the quality of care by focusing on educating patients and providing scientificallybased, uniform clinical care for specific conditions. Patient selfmanagement is believed to improve health outcomes and reduce costs because patients who take an active role in the management of their disease understand the importance of daily and continuous care, establish open relationships with their healthcare provider and are more likely to adhere to a disease management plan developed by the healthcare provider based on the patient's abilities. ${ }^{45}$ Disease management programs facilitate patient self-management and quality improvement by using a collaborative teamwork approach to providing care. This collaborative approach lessens the likelihood of substandard delivery of care, patient dissatisfaction, communication breakdown and care interruption. ${ }^{46}$ The disease management team (e.g., physicians, nurse practitioners, nurses, physician's assistants and other staff) involved in providing patient care shares responsibilities so that each member of the team is using his time to provide service within his

\footnotetext{
${ }^{44}$ Disease Mgmt. Ass'n of America, Definition of Disease Management, at http://www.dmaa.org/definition.html (last visited Mar. 10, 2003).

${ }^{45}$ Howard Glecman \& John Carey, An Apple a.Day--On the Boss, BUSINESSWEEK, Oct. 14, 2002, at 122. This has also been referred to as "patient-centered care." COMM. ON QUALITY HEALTH CARE, IOM, CROSSING THE QUALITY CHASM 48-51 (2002).

${ }^{46}$ Alicia M. Conill \& David A. Horowitz, Disease Management: Origins, Basic Concepts and Practical Considerations, 2 SEMINARS IN MEDICAL PRACTICE 10 (1999).
} 
expertise and is being adequately compensated for his services. Finally, evidence-based medicine improves outcomes and quality by establishing guidelines and protocols based on indicators and benchmarks determined through randomized, controlled clinical trials and evaluated by medical experts. ${ }^{47}$ By adopting these best-practices in healthcare, disease management programs ensure that their patients receive the highest quality and most appropriate treatment available.

Disease management programs also achieve quality by creating mechanisms for continuous improvement. Using information technology to evaluate and monitor patient outcomes and aggregate data, disease management programs can determine what techniques work and do not work for their patient population and adjust their practices accordingly. ${ }^{48}$ Evidence-based indicators and key measures also allow for the routine creation of reports for progress assessment. These reports can serve as the basis for determining whether and where structural improvements are needed. Feedback loops are also created in disease management programs through open-lines of communication between the patient and his disease management team. By discussing care with individual patients, the teams can determine if changes in the program are necessary to meet a patient's needs and disease management goals.

Although disease management programs primarily espouse a desire to achieve quality, they also indirectly can achieve equality in healthcare by reducing racial disparities. ${ }^{49}$ The uniform clinical care provided to all patients involved in a disease management program can reduce disparate provision of healthcare due to socioeconomic status, race or ethnicity. Because every individual is receiving care derived

${ }^{47}$ See generally Evidence-Based Medicine Working Group, Evidence-Based Medicine: $A$ New Approach to Teaching the Practice of Medicine, 268 JAMA 2420, 2420-25 (1992) (discussing the paradigm shift to evidence-based medicine and its influence on clinical practice). The concept of evidence-based medicine in its present form was developed by a workgroup assembled at McMaster University. Id. This paradigm emphasizes applying the evidence from the scientific literature into day-to-day clinical practice. Id. at 2421. The shift to evidence-based medicine is founded on the premise that physicians who possess traditional medical skills of understanding the pathophysiology of human disease and sensitivity to patients' emotional needs can provide superior care by appropriate interpretation of the results from clinical research. Id. at 2421-22.

${ }^{48}$ Id.; COMM. ON QUALITY HEALTH CARE, IOM, supra note 45, at 97-101.

${ }^{49}$ This indirect approach is echoed in a recent quote from Donna Brazile, a leading Democratic Party strategist: "Our civil rights agenda can't be based on what happened 30 or 40 years ago .... This country is already polarized along racial lines, and dwelling on that doesn't play to our advantage. What plays in the middle is sensible, sound ideas of how to move America forward. This means focusing on issues that help all races, like educational opportunity and the economy." Katherine Q. Seelye, Divisive Words: The Democrats; Agile Switch by Senate Republicans Steals Democrats' Gathering Thunder, N.Y. TIMES, Dec. 24, 2002, at A18. 
from the same evidence-based guidelines, there is little room for conscious or unconscious biases to affect the quality of care. ${ }^{50}$ The creation of information systems infrastructure and systematic monitoring further diminishes the possibility for variation in the provision of healthcare on the basis of either conscious or unconscious biases. Finally, the shift in focus towards chronic care diseases has a positive effect, especially for racial and ethnic minorities.

\section{Reformist Institutions: Two Exemplary Projects}

Healthcare systems are implementing programs to provide equitable healthcare via a disease management approach. The Health Disparities Collaboratives and programs within certain physician-led managed care systems are two exemplary projects that have adopted this method. The Health Disparities Collaboratives demonstrates a shift to a disease management approach within the community health center system that has traditionally served racial and ethnic minorities. Physicianled managed care organizations have also embarked on emphasizing quality by creating disease management programs to improve outcomes, to attract patients and to provide cost-effective service.

\section{Community Health Center Based System}

The federally funded Health Disparities Collaboratives is a comprehensive initiative to address racial, ethnic and socioeconomic health disparities through disease management. ${ }^{51}$ This program is part of the Healthy People 2010 Campaign to (1) increase the quality of healthy life for all Americans and to (2) eliminate health disparities through the use of evidence-based medicine, which entails

${ }^{50}$ Critics, however, are wary of evidence-based medicine, and consequently disease management programs, because the studies on which the developed guidelines for practice are based focus, primarily, on white male subjects. See, e.g., Bowser, supra note 3. In response to this critique, the National Institutes of Health has published standards for the approval of research protocols that require the inclusion of women and minorities. The first guidelines for the inclusion of women and minorities in research involving human subjects were published in 1994. The most recently amended version of the guidelines was published in October of 2001, available

at http:/grants.nih.gov/grants/funding/women_min/guidelines_amended_10_2001.htm. However, for many common diseases, randomized-controlled trials still have not been conducted on women and minorities. Nonetheless, the provision of some level of uniform care and the basic preventive and primary care services found in many disease management programs are more beneficial than the variability of the past. Disease management also provides the opportunity to incorporate variables, such as race and gender, into guidelines as study results become available.

\footnotetext{
${ }^{51}$ Health Disparities Collaboratives, A National Effort to Improve Health Outcomes for All Medically Underserved People with Chronic Disease., at http://www.healthdisparities.net (A website dedicated to providing information and resources "for poor, minority, and other underserved people") (last visited Mar. 10, 2003).
} 
incorporating key scientific findings into medical practice and measuring the associated outcomes. ${ }^{52}$.

\section{Background}

The Health Resources Services Administration (HRSA) created the Health Disparities Collaboratives program. In the late 1990s, HRSA sought to improve healthcare quality and outcomes at community health centers, which serve predominantly low-income, racial and ethnic minority populations. ${ }^{53}$ Using the Collaborative Chronic Care Model for disease management, developed by the Institute for Healthcare Improvement (IHI) and the MacColl Institute, as a guide, HRSA created the Health Disparities Collaboratives program, devised a two-phase implementation plan and allocated funding for five years beginning in $1998 .^{54}$ The first phase of implementation involves all 750 federally-funded community health centers and 4,000 primary care sites in a collaborative learning experience dedicated to one or more health disparities by the year 2005 . $^{55}$ The second phase will spread this work throughout the community health center network in all health disparities areas by the year $2010 .^{56}$ Community health centers participating in the program attend national conferences, an integral part of the educational experience, receive access to an otherwise notin-the-public-domain registry and obtain training on how to implement the disease management approach at their respective site. No funding,

${ }^{52}$ Office of Disease Prevention \& Health Promotion, supra note 9.

${ }^{53}$ Telephone Interview with Rebecca Steinfield, IHI (July 8, 2002); Interview with Staff, Holyoke Health Ctr. in Holyoke, Ma. (Oct. 29, 2002) (seventy-five to eighty-five percent of patients are Latino) [hereinafter Holyoke Staff Interview]; Interview with Staff, Lynn Health Ctr. in Lynn, Ma. (Oct. 22, 2002) (sixty percent of patients are Medicaid and five to ten percent are uninsured) [hereinafter Lynn Staff Interview]. The Health Disparities Collaboratives' partners include IHI, governmental agencies and associations representing organizations and healthcare providers that work with disadvantaged populations, including the National Association of Community Health Centers, Health Care for the Homeless Clinicians' Network and the Migrant Clinicians Network. The Improving Chronic Illness Care Program (ICIC), funded by the Robert Wood Johnson Foundation and housed at the MacColl Institute, also serves as a partner. ICIC conducts a separate program utilizing the same, or similar, models as the Health Care Disparities Collaboratives for healthcare organizations that are not eligible for the federal program. The Robert Wood Johnson Foundation also provides additional funding through grant programs to community health centers involved in the Health Disparities Collaboratives. Telephone Interview with Eva Cohen, Northeast Cluster Coordinator, Health Disparities Collaboratives (June 29, 2002) [hereinafter Cohen June Interview]; Improving Chronic Illness Care, A Nat'l Program of the Robert Wood Johnson Found, at http://www.icic.org (A website committed to "helping the chronically ill through quality improvement and research") (last visited Mar. 10, 2003); Robert Wood Johnson Found., at http://www.rwjf.org (last visited Mar. 10, 2003).

\footnotetext{
${ }^{54}$ Cohen June Interview, supra note 53.

${ }_{55}^{55}$ Health Disparities Collaboratives, supra note 51.

${ }^{56} I d$.
} 
however, is given to compensate for the time clinicians spend working within the program rather than rendering billable services, or for hiring additional staff (e.g., an information system specialist). ${ }^{57}$

The first Health Disparities Collaboratives program was launched in the fall of 1998 at five community health centers focusing on the treatment of diabetes. ${ }^{58}$ A second collaborative for diabetes involving additional sites was initiated in October of $1999 .^{59}$ Over the last three years, the program has grown and the number of diseases focused on has expanded. Of the 131 community health centers selected nationally to participate in the Health Disparities Collaboratives during the 20022003 cycle, however, diabetes collaboratives continue to be the most popular $(47 \%)$, followed by depression $(25 \%)$, cardiovascular disease $(15 \%)$ and asthma $(12 \%){ }^{60}$

\section{Organization}

The Health Disparities Collaboratives has a tri-level (national, regional and local) organizational and management structure. At the national level, the Bureau of Primary Health Care (BPHC), located within HRSA, serves as the administrative and funding body. ${ }^{61}$ The BPHC Health Disparities Collaboratives Director provides leadership for Collaboratives' operations, management and evaluation. ${ }^{62}$ BPHC grants fund travel for community health center teams to attend four national conferences annually and funding for development of the necessary information systems infrastructure during the twelve to fourteen month program. ${ }^{63}$ BPHC also provides Regional Cluster staff support and assembles a national expert panel to update the clinical practice guidelines used in the Collaboratives. ${ }^{64}$

The Health Disparities Collaboratives is organized into five Regional Clusters of states. ${ }^{65}$ Through a competitive process, a state Primary Care Association is selected as the lead organization within each Regional Cluster. ${ }^{66}$ The lead organization is responsible for organizing regional conferences, coordinating regional communication through conference calls and an e-mail listserv, assisting community

\footnotetext{
${ }^{57}$ Telephone Interview with Eva Cohen, Northeast Cluster Coordinator, Health Disparities Collaborative (Nov. 12, 2002) [hereinafter Cohen Nov. Interview].

${ }^{58}$ Telephone Interview with Rebecca Steinfield, supra note 53.

${ }^{59}$ Health Disparities Collaboratives, supra note 51 .

${ }^{60}$ Cohen Nov. Interview, supra note 57.

${ }^{61}$ Health Disparities Collaboratives, supra note 51.

${ }^{62} I d$.

${ }^{63}$ Cohen June Interview, supra note 543; Health Disparities Collaboratives, supra note 51.

${ }^{64}$ Cohen Nov. Interview, supra note 57.

${ }^{65}$ Health Disparities Collaboratives, supra note 51.

${ }^{66}$ Cohen June Interview, supra note 53.
} 
health centers in the region and reviewing their monthly reports. ${ }^{67}$ The Regional Clusters also offer annual reunions for teams to "sustain and spread"--to continue the work they have done and to apply what they have learned to other efforts in which they are involved. ${ }^{68}$ Recently, limited funds to assist in this effort have been made available by BPHC to several teams. ${ }^{69}$

The cornerstone of the Health Disparities Collaboratives, as established by the IHI Learning Model, is communication and networking among participating community health centers. ${ }^{70}$ The four annual national conferences are an essential element in the learning and collaboration process for the participating community health centers. These conferences provide an opportunity to exchange ideas and to discuss individual program successes and barriers. Community health centers are also able to connect with each other through conference calls, email listservs and web-based support. The regional and national staffs facilitate this process and provide structure and support through monthly faculty reviews and assistance in troubleshooting."

At the national conferences, the participating community health centers learn how to utilize clinical practice guidelines for the chronic illnesses on which they are focusing and how to systemically apply these guidelines to their patients and, more broadly, the healthcare delivery system. In the interim between these learning sessions, participants apply what they have learned at the local level. While active in the program, community health centers also learn the PlanDo-Study-Act (PDSA) cycle from the Model for Improvement. ${ }^{72}$ The PDSA method works to allow a health center to implement disease management strategies that achieve pre-defined goals (e.g., decrease the HbAlc levels in the center's patients with diabetes or increase the use of anti-inflammatory medications in a center's patients with persistent asthma). Using this method, community health centers learn how to effectively self-evaluate and how to respond to problems and

\footnotetext{
${ }^{67} I d$.

${ }^{68} I d$.

${ }^{69}$ Id.

${ }^{70} \mathrm{IHI}$, at http://www.ihi.org (A website "offering resources and services to help health care organizations make dramatic and long-lasting improvements that enhance clinical outcomes and reduce costs") (last visited Mar. 10, 2003).

"Cohen June Interview, supra note 53.

${ }^{n}$ Health Disparities Collaboratives, supra note 51. The Model for Improvement was developed by the Associates in Process Improvement based on three questions: (1) What are we trying to accomplish?; (2) How will we know that a change is an improvement?; and (3) What changes can we make that will result in any improvement? Telephone Interview with Rebecca Steinfield, supra note 53. This model was combined with the IHI Learning Model to create structure and a support system. Id.
} 
inefficiencies identified through changes over time during PDSA cycles.

Creating a network within the larger community (termed "Community Linkages") to better serve patients is also a key component of the Health Disparities Collaboratives. Many community health centers already have extended networks including, among other players, community organizations, local and state public health departments and schools. ${ }^{73}$

\section{Essential Elements of the Program}

In order to participate in Health Disparities Collaboratives, a community health center must abide by evidence-based medicine practice guidelines, recognize that the program is population-based and understand that the collaborative is not a research project but a new way of providing care. ${ }^{74}$ The community health center must agree to commit the necessary resources and time and to adhere to the program's reporting requirements, including the submission of a narrative report on a quarterly basis and data on a monthly basis. ${ }^{75}$ By joining the program, the community health center pledges to continue practicing in accord with the Health Disparities Collaboratives' model into the future. $^{76}$

The outcome goals for each community health center are set by the national agency when the community health center joins the program. Each participating community health center must monitor and report on national shared measures for tracking improvement that have been identified based upon established, clinical guidelines. The monitoring process is dependent on each community health center creating information systems infrastructure to support data entry. Each community health center must create a registry of patients in which patient data can be, and is, tracked electronically. ${ }^{77}$ To facilitate the implementation of required technology, BPHC offers a multi-condition registry template (software) for centers to use and the Health Disparities Collaboratives provides technical support from information systems specialists. ${ }^{78}$ Baseline data are collected on each center's patient population living with a specific disease prior to instituting the Collaborative protocol. Data on key measures are then tracked through patient visits over the twelve months of active Collaborative

\footnotetext{
${ }^{73}$ Lynn Staff Interview, supra note 53; Holyoke Staff Interview, supra note 53.

${ }^{74}$ Cohen June Interview, supra note 53.

${ }^{75}$ Id.

${ }^{76} I d$.

"Id:; Health Disparities Collaboratives, supra note 51.

${ }^{78}$ Health Disparities Collaboratives, supra note 51.
} 
participation. Each community health center must generate a monthly data report for evaluation to determine whether there has been demonstrated improvement in patient healthcare status. ${ }^{79}$ These regular monthly summary reports provide feedback to the community health center, the Regional Cluster and the national panel regarding the status of the program at each site. ${ }^{80}$

One of the key measures used to track a community health center's success is the number of patients with a "patient contract" or selfmanagement strategy. ${ }^{81}$ Patient contracts are made and documented during each patient visit to the health center. These contracts reflect the Health Disparities Collaboratives' focus on getting patients involved in their own care by educating them on the basics of their disease and its management by regularly communicating with them regarding actions that can improve outcomes and by working to overcome barriers to treatment, including cultural and language barriers. For example, patients are taught to integrate health-monitoring activities into their daily routine, such as self-measuring blood glucose levels for diabetic patients and managing diet and exercise. Group visits with clinicians and other patients with the same illness may also be used to educate patients on how to manage their disease. ${ }^{82}$

To comply with the program, community health centers also need to redesign the delivery of care by adopting a teamwork approach. Clinicians (e.g., physicians, nurse practitioners and physicians' assistants) must be able to delegate authority to other trained staff for routine care that can be provided via standing orders (e.g., performing foot exams on diabetic patients, making certain referrals or ordering routine labs) ${ }^{83}$ This allows clinicians to better use their time for patients in need and for tasks that require medical expertise. In addition, this cooperative approach allows health centers to better meet patients' expectations for quality care by allowing for culturally competent and language-appropriate services, adequate follow-up care and more time for patient education and communication.

One of the key reasons that equity might be achieved through the Health Disparities Collaboratives project is that each community health center must determine how to ensure positive outcomes for their

\footnotetext{
${ }^{79}$ Cohen June Interview, supra note 53; Health Disparities Collaboratives, supra note 51.

${ }^{80}$ Cohen Nov. Interview, supra note 57; Health Disparities Collaboratives, supra note 51.

${ }^{81}$ Cohen Nov. Interview, supra note 57.

${ }^{82}$ Telephone Interview with Veronica Richardson, IHI Nat'l Collaborative Dir., and Cindy Hupke, IHI Nat'l Collaborative Dir. (Nov. 20, 2002).

${ }^{83}$ Health Disparities Collaborative, About Us, at http://www.healthdisparities.net/about.html (last visited Mar. 10, 2003) (stating that the delivery of healthcare must "transform . . . through models of care, improvement and learning").
} 
particular population of diverse patients. Each health center has a similar set of goals and tools, including technology and training, but each has to ascertain how to make these systems work for their particular "territory." The emphasis on community-based primary care allows the health centers to emphasize the best patient-based management for their population.

At the community health center in Holyoke, Massachusetts, for example, the patients are primarily Puerto Ricans. ${ }^{84}$ In order to meet the needs of this particular community, the center uses local staff to teach nutrition and to restate scientific knowledge in a way that is understandable both in language and concept. The center refines and adapts the protocols that work for its patients through the feedback system (Plan-Do-Study-Act) taught through the educational portion of the Health Disparities Collaboratives program. This system gives the center a framework, but allows it to adjust its care practices to its population's specific needs. The center also uses technology to monitor the health status of its patients. The center has developed and maintains patient registries, which allow the staff to access and track information on every patient. Thus, the center can improve individual care.

\section{Physician-Led Managed Care System}

While the Health Disparities Collaboratives is focused on implementing disease management programs for the particular subset of patients who seek care at community health centers, ThedaCare (Touchpoint Health Plan) and the Marshfield Clinic (Security Health Plan) are two Wisconsin-based healthcare delivery systems that have successfully adopted programs based on quality improvement and have extended their disease management programs to all patients in their health plans. Notably, both have achieved positive outcomes for their Medicare/Medicaid patients, even with those programs' associated lower reimbursement rates for care. ${ }^{85}$

ThedaCare is a community-owned health system, including Touchpoint Health Plan, which serves the northeast Wisconsin region. ${ }^{86}$ ThedaCare is a physician-led organization in which physicians hold leadership positions as members of the board of directors and are

\footnotetext{
${ }^{84}$ Holyoke Staff Interview, supra note 53.

${ }^{85}$ Telephone Interview with Ron Harms, Medical Director, Touchpoint Health Plan (Dec. 3, 2002); Promoting Disease Management in Medicare: Hearing on H.R. 4954 Before the Health Subcomm. of the House Comm. on Ways and Means, 107th Cong. 4-9 (2002) (statement of Michael Hillman, Medical Director of Business and Community Health Services), available at http://waysandmeans.house.gov/legacy/health/107cong/4-16-02/416hill.htm.

${ }^{86}$ ThedaCare, Who We Are, at http://www.thedacare.org/about/thedacare.html (last modified Feb. 20, 2003).
} 
consulted when making business decisions. ${ }^{87}$ ThedaCare has heightened its focus on clinical care and has become a strong advocate for systemic quality improvement in the state of Wisconsin. Since 1998, ThedaCare has been adopting IHI models for inpatient and outpatient care. ${ }^{88}$ In order to continuously reevaluate its protocols and to improve the quality of care, ThedaCare regularly collects data on quality indicators, monitors outcome measures on its patients and provides incentives to providers who meet quality goals. ${ }^{89}$ ThedaCare also relies heavily on outside evaluation and accreditation by the National Committee on Quality. Assurance (NCQA) to create improvement strategies and to validate the success of its own efforts. In 2002, Touchpoint Health Plan was the strongest overall performer nationwide on the Health Plan Employer Data Information Set (HEDIS) results included in NCQA Accreditation. ${ }^{90}$

Security Health Plan has also performed well according to NCQA Accreditation standards and has been named one of the top fifteen accredited health plans in the country. ${ }^{91}$ It is a physician-directed managed care health plan owned and operated by Marshfield Clinic. ${ }^{92}$ The Clinic, a physician-owned and managed health system that serves a largely rural population in northern, central and western Wisconsin, is another strong proponent of focusing on quality in medical care. ${ }^{93}$

Marshfield Clinic has actively attempted to institute disease management programs focusing on areas such as diabetes, prenatal health, congestive heart failure, asthma, lifestyle management, secondary cardiac prevention and anticoagulation management. ${ }^{94}$ The

\footnotetext{
${ }^{87}$ Id.

${ }^{88}$ Bernard Wysocki, Jr., Doctor Prescribes Quality Control for Medicine's Ills, WALL STREET JOURNAL ONLINE, May 30, 2002 available at http://webreprints.djreprints.com/00000000000000000025422001.html.

${ }^{89} \mathrm{Nat}$ 'l Comm. for Quality Assurance, 'State of Health Care Quality: 200219 (2002), available at http://www.ncqa.org/Communications/Publications/index.htm.

${ }^{90}$ Id. at 18; see generally Nat'l Comm. on Quality Assurance (NCQA), at http://www.ncqa.org (last visited Mar. 10, 2003). The NCQA is an independent, non-profit organization that administers accreditation and performance measurement programs for managed healthcare plans. Id. Health Plan Employer Data Information Set (HEDIS) is a set of standardized performance measures that is sponsored, supported and maintained by NCQA. Id. It is designed to compare the performance of managed healthcare plans and its measures include many significant public health-related issues and consumer experiences. Id. NCQA accreditation is also used to meet licensing standards in many states. Id.

${ }^{91}$ Press Release, Security Health Plan, Security Health Plan Names Among 15 Best HMOS (Sept. 26, 2002), available at http://www.securityhealth.org/pr_ncqa15.asp.

${ }^{92}$ Security Health Plan, Facts About Security Health Plan of Wisconsin, Inc., at http://www.securityhealth.org/visitors_facts.asp (last modified Mar. 21, 2002).

${ }^{93}$ Marshfield Clinic, NewsRoom Fact Sheet, at http://www.marshfieldclinic.org/mc.facts/ (last visited Feb. 20, 2003).

${ }^{94}$ Promoting Disease Management in Medicare: Hearing on H.R. 4954 Before the Health Subcomm. of the House Comm. on Ways and Means, supra note 85, at 7.
} 
clinic's goal is to provide continuity of care within the system by identifying at-risk patients and pursuing active case management. Typically, patients are introduced into the disease management program on the recommendation of their physician. The patients are entered into a special tracking database for monitoring purposes and condition-specific assessments are performed by registered nurses via telephone. For condition-specific interventions, the patient and nurses customize a curriculum of educational messages and behavioral coaching based on the patient's current knowledge base and the degree to which the patient is at-risk. A team of clinicians, including the case manager (usually a nurse), the Medical Director of the program and the patient's physician provide active case management including continuous assessment, monitoring and, if necessary, intervention. All interactions with the patient are documented in the tracking database and the electronic medical record. ${ }^{96}$ A provider care plan is developed and checked against national guidelines.

\section{LEARNING FROM THE EXEMPLARY PROJECTS: REDESIGNED HEALTHCARE GOVERNANCE FRAMEWORKS}

The two exemplary projects are working to provide high quality, equitable care. Patient participation, multidisciplinary teams and community involvement are integrated with standard setting, data collection and feedback. These projects combine diversity at the patient and organizational level with coordination at the regional and national level. Dissemination of this framework beyond the exemplary projects, however, will require overcoming extensive barriers that preserve the status quo. These barriers can be described as wicked problems, narrow knowledge, inappropriate consumer voice, inflexible rules, traditional federalism and stalled technological integration. There is a route around and over the barriers that the exemplary projects explore and build upon. This route leads to a redesigned relationship between local and national entities, network learning, and public and private coordination.

\section{Barriers to Embedding the Quality Framework}

One barrier to innovation in the healthcare system is the fragmentation of power and policy among traditional regulatory agencies. Without the power to implement policy changes throughout the entire healthcare system, these agencies do not have the capability to solve problems. This barrier is what analysts in the United Kingdom have termed

\footnotetext{
${ }^{95}$ Id. at 6-7.

${ }^{96} \mathrm{Id}$. at 6-8.
} 
"wicked problems."197 In the healthcare domain, a wicked problem is illustrated by the split between publicly funded and regulated programs such as Medicare and Medicaid and employer-based healthcare coverage.

Another barrier to innovation is the "narrow knowledge" provided to actors within the healthcare system. Actors are trained early on to play a specific role within the system and are educated with only the knowledge necessary to play that role. $^{98}$ For example, insurance regulators do not understand the clinical aspects of healthcare and, therefore, have difficulty designing a regulatory system that allows physicians to expand and build on their clinical knowledge. Conversely, physicians do not understand the way traditional regulation works and cannot design their clinical goals to be implemented within the regulatory structure.

Attributing an inappropriate voice to consumers in the system also stalls innovative efforts. It is often said that consumers have the ability to effect change in the healthcare system through market mechanics. Yet, in an environment where consumers have relatively little choice in the plan in which they enroll, this voice is, essentially, muted. By putting faith in the effectiveness of market-based consumer participation and not seeking an alternative way for consumers to exert influence, the system creates a barrier to change because consumers are prevented from assuming an active role.

The inflexible and punitive administrative and judicial rules placed on healthcare professionals pose another barrier. Healthcare professionals have vigorously fought against regulatory systems, such as certification, or common law systems, such as medical malpractice, which work against their commitment to professional values, such as autonomy and service. ${ }^{99}$ These regulatory systems create resistance among healthcare professionals to participation in collaborative enterprises for redesigning the regulatory framework that will provide quality care.

\footnotetext{
${ }^{97}$ John Peterson \& Laurence J. O'Toole, Jr., Federal Governance in the United States and the European Union: A Policy Network Perspective, in THE FEDERAL VISION 300, 305 (Kalypso Nicolaidis \& Robert Howse eds., 2001). These problems have also been called "silo" problems in the United States. Joanna Weiss \& Anthony Flint, Romney Picks 2 as Agencies' 'Chiefs' Cabinet Structure Gets a Revamping, BOSTON GLOBE, Dec. 20, 2002, at A1.

${ }^{98}$ Louise G. Trubek \& Jennifer J. Farnham, Social Justice Collaboratives: Multidisciplinary Practices for the People, 7 CLINICAL L. REV. 227, 257 (2000).

${ }^{99}$ See, e.g., Larry I. Palmer, Patient Safety, Risk Reduction and the Law, 36 HOUS. L. REV. 1609 (1999); Lisa E. Bartra, Reconsidering the Regulation of Health Professionals in Kansas, 5 KAN. J.L \& PUB. POL'Y 155 (1996).
} 
Traditional federalism and the disconnect between the power to fund and the provision of care also create a barrier to innovation. Organizations that deliver primary healthcare are based at local sites staffed by local professionals and visited by local patients. Shifts in the quality of care, both good and bad, occur at this local level yet the funding and regulatory power is based at the state and federal levels. This disconnect prevents local sites from spreading innovative practices and protects poor performance. In addition, it inhibits state and federal governments' ability to create accountable systems.

Finally, the healthcare industry is notable for its resistance to the utilization of technology as a method for accountability and shared information. Healthcare professionals have been wary of technological change for fear that data would be used inappropriately. The resulting lack of uniform standards for encoding data has hindered efforts to learn from aggregated data and to gain shared experiential knowledge.

\section{Aspects of the Redesigned Healthcare Governance Framework} The exemplary projects discussed earlier faced these barriers as they attempted to incorporate a chronic care disease management approach into their healthcare treatment. In order to improve their delivery of services, they changed not only the individual patient care model, but developed the broader frameworks necessary for improving services. Their innovative vision required a redesigned framework to enable improved outcomes. In order to overcome the resistances to changing the framework, the exemplary projects realigned the relationship of national, regional and local entities, increased the use of networks for information sharing and linked public and private institutions.

\section{Recalibrating Federalism}

One approach to overcoming the barriers to changing the framework is to realign the relationship between the various levels of government. This realignment would allow the governmental levels to perform different functions and permit alternate systems to emerge for overcoming the barriers to change.

Local and state agencies are exerting more of a leadership role in designing and funding healthcare coverage and delivery systems. This localization of governance is in contrast to the traditional expectation that federal administrative agencies provide the solution to social, political and economic problems. ${ }^{100}$ Within this vertical shift of function, the local and state agencies are taking on a larger role and the

\footnotetext{
${ }^{100}$ See Louise G. Trubek, Lawyering for a New Democracy: Public Interest Lawyers and New Governance: Advocating for Healthcare, 2002 WIS. L. REV. 575 (2002).
} 
federal agencies are reacting by performing different functions including setting standards, monitoring compliance and providing incentives.

The Health Disparities Collaboratives illustrates a realigned multilevel interaction between local, regional and national players. Community health centers at the local level constantly interact with regional and national supervisors through the transmission of data and national training programs. Thus, community health centers are held accountable to the regional and national agencies. At the same time, neither the national nor the regional agencies prescribe exactly how the community health centers should collect data or meet the indicators. Rather, community health centers are encouraged to design a program that fits the needs of their local population. The national and regional staff can provide guidance to overcome some of the difficulties that a particular community health center may be facing, but they do not profess to be experts on exactly how a program should be implemented to meet a specific population's needs.

To maintain influence, the federal government may provide funding incentives to health centers to adopt disease management programs. Some evidence suggests that the federal government ties its base grants to community health centers to participation in the Health Disparities Collaboratives. Control over funding allows the federal government to push the spread of the disease management model to every community health center and to embed quality into a set of core principles.

In addition to national coordination, the Health Disparities Collaboratives also has a regional level of coordination. This regional participation provides a level of coordination closer in scope and geography to the local level and provides supervision at a level that can better comprehend the particular patient and community mix being dealt with at the local level. The regional groups are accessible to the local health centers and can provide timely information and feedback.

The role of scientific knowledge and data gathering and use in the Health Disparities Collaboratives program also illustrates the realignment of national, regional and federal governments. The national agency provides scientific knowledge to the local community health centers. The local health centers then experiment with this knowledge in the context of individual patients and groups of patients within the community. The data gathered at the community health center is returned to the national agency for evaluation and for the refinement and redesign of future grants. Finally, the health centers use the data and conclusions drawn from the data to generate grant proposals. Their 
previous experience with data collection gives them a significant advantage in obtaining local and state funding.

\section{Learning Across Networks}

In addition to the vertical realignment described above, the exemplary projects also illustrate a horizontal movement. ${ }^{101}$ This horizontal movement helps to overcome the barriers to change because it entails the spreading of knowledge and information across geographically and culturally diverse local sites, different professional communities and competing stakeholders. The proliferation of networks is a result of the need for "mutuality and interdependence as opposed to hierarchy and independence." ${ }^{102}$ Three types of networks appear in the exemplary projects: shared learning networks, community networks and policy networks.

Shared learning networks consist of same or similar organizations with common goals. ${ }^{103}$ Within the Health Disparities Collaboratives there is substantial exchange of knowledge among the health centers using email listservs and learning sessions. This informal shared learning of experiences allows discussion of successes and failures, and encourages new experiments without the use of detailed rules. Participants in the Health Disparities Collaboratives often identify these networking "tools" as one of the major accomplishments of the program. The physician-led managed care organizations also rely heavily on networks for sharing data from which they can derive reliable information to use in improving outcomes. These networks of physician-led managed care organizations are networks of similar people working with similar goals. They transfer knowledge and learn from each other.

Community networks of different types of organizations with mutual objectives are also emerging in the healthcare landscape. Community health centers and other healthcare organizations often have established relationships with other community organizations, local and state public health departments and schools. ${ }^{104}$ These

\footnotetext{
${ }^{101}$ This horizontal movement is sometimes called networked governance. See generally Peterson \& O'Toole, supra note 97; Louise G. Trubek, Health Care and Low Wage Work in the U.S.: Linking Local Action for Expanded Coverage, in RECONFIGURING WORK AND WELFARE IN THE NEW ECONOMY: A TRANSATLANTIC DIALOGUE (Jonathan Zeitlin \& David M. Trubek eds., 2003).

${ }^{102}$ Peterson \& O'Toole, supra note 97 , at 300.

${ }^{103}$ See, e.g., IHI, Resources, Links, at http://www.ihi.org/resources/weblinks (last visited Mar. 10, 2003) (describing the Group Practice Improvement Network as a shared learning network "that focuses on better clinical outcomes, improved access to care, greater ease of consumer use, cost-effectiveness, and high satisfaction among users of the health care system, their families, and the community").

${ }^{104}$ Holyoke Staff Interview, supra note 53; Lynn Staff Interview, supra note 53.
} 
networks can work together to publicize the availability of services in community health centers, to provide care in places outside of the community health center and to link with programs that also work to help patients achieve better health status. ${ }^{105}$ In Massachusetts, for example, community health centers participate in the Healthy Homes project, a state project in which all interested people cooperate to improve housing conditions, such as getting rid of mold that might contribute to asthma. ${ }^{106}$ In addition, the community health center in Lynn, Massachusetts, one of the Health Disparities Collaboratives sites, uses schools as the locations for identifying patients and working on health issues among the students. ${ }^{107}$ This allows the health center both to track its patients in the schools and to identify new patients.

Both ThedaCare and the Marshfield Clinic have also formed important community linkages. ThedaCare conducts classes and holds events for the community, co-sponsored by local businesses and organizations on health topics of interest. ${ }^{108}$ Marshfield Clinic, through its research foundation, conducts community outreach as a member of the Northwoods Coalition. ${ }^{109}$ The Coalition is a partnership of community organizations, ethnic communities and other affiliated groups, including law enforcement, schools and faith-based organizations. ${ }^{110}$ One of the programs within the coalition is Project Forward, a community-based initiative designed for youths to strengthen local efforts to address behavioral health issues, particularly alcohol, tobacco and other drug abuse related problems. ${ }^{11}$ The program is supported by the Center for Community Outreach at the Marshfield Clinic and its educational program, the Youth Development Institute. ${ }^{12}$ Project Forward also places full-time AmeriCorps members in interested communities that are seeking to combat youth alcohol and drug abuse. ${ }^{113}$

${ }^{105}$ Lynn Staff Interview, supra note 53.

${ }^{106}$ Holyoke Staff Interview, supra note 53.

${ }^{107}$ Lynn Staff Interview, supra note 53.

${ }^{108}$ See ThedaCare, Community Education and Service, at http://thedacare.org/events/index.html (last visited Mar. 10, 2003).

${ }^{109}$ See Ctr. for Comm. Outreach, Marshfield Clinic, Community for Community Outreach Organizational Chart, at http://research.marshfieldclinic.org/cco/orgchrt.asp (last modified Apr. 9, 2001).

${ }^{110} \mathrm{Ctr}$. for Comm. Outreach, Marshfield Clinic, Northwoods Coalition, at http://research.marshfieldclinic.org/cco/northwoods.asp (last modified Apr. 9, 2001).

"Itr. for Comm. Outreach, Marshfield Clinic, Project Forward, at http://research.marshfieldclinic.org/cco/project_forward.asp (last modified Apr. 9, 2001).

${ }^{112} \mathrm{Ctr}$. for Comm. Outreach, Marshfield Clinic, Youth Development Institute, at http://research.marshfieldclinic.org/cco/yd_institute.asp (last modified Apr. 9, 2001).

${ }^{113} \mathrm{Ctr}$. for Comm. Outreach, Marshfield Clinic, Current Programs of the Community for Community Outreach, at http://research.marshfieldclinic.org/cco/cco.asp (last modified Apr. 9 , 2001). 
A third type of network appearing is the policy network, in which a wide range of stakeholders who seem to have disparate interests meet to share knowledge and to resolve what seem to be unsolvable problems. ${ }^{114}$ For example, the implementation of the Health Disparities Collaboratives is due, in part, to the interaction between equity advocates and quality reformers. In order to advance their separate agendas, each group needed support from the other. These collaborations among stakeholders encourage the sharing of information, influence healthcare practice and seek to affect public policy.

\section{Linking Public and Private: Institutions, Payment Systems and Regulation}

The traditional divide between market-driven and government-run institutional and legal structures creates barriers to embedding quality by rigidly enforcing bright-lines that inhibit the interchange of information and skills. Creating a link between the public and private can overcome these barriers. Community health centers, for instance, are nonprofit organizations run by community boards. ${ }^{115}$ They have historically served disadvantaged populations. Like other healthcare organizations, community health centers rely on reimbursement for services from patients through third party reimbursement from private insurance, Medicare and Medicaid. Community health centers must also seek federal funding and other support, however, because of a high patient population of uninsured, Medicare and Medicaid patients. Federal funding and certification combined with private foundation and

\footnotetext{
${ }^{114}$ Peterson \& O'Toole, supra note 97, at 304-05; Carl Ameringer, Patients, Providers and Attorneys: Holding Managed Care Accountable for Health Care Decisions (Nov. 2001) (unpublished paper, on file with author).

${ }^{115}$ The federal government first began funding of community health centers in the $1960 \mathrm{~s}$ as part of President Johnson's "war on poverty" to accomplish his vision of a "Great Society." Under the Economic Opportunity Act (EOA), many neighborhood community health centers were established in the early 1970s. The Public Health Service began funding community health centers in 1969 and was granted authority over them in the 1970s. Often struggling, in the 1980s they survived by emphasizing good management and seeking diverse sources of funding. Currently, the federal grant program for community health centers is authorized under the Health Centers Consolidation Act of 1996 as section 330 of the Public Health Service Act and administered through BPHC/HRSA. This Act consolidated Community Health Centers, Migrant Health Centers, Health Care for the Homeless programs and Public Housing Primary Care programs under a single statutory umbrella that provides targeted funding. BPHC/HRSA also recommends certification of community health centers for designation as federally qualified health centers (FQHC) to the Centers for Medicare and Medicaid Services (CMS). As community health centers continue to rely greatly on private support, the Act also gave more flexibility to community health centers in using non-federal funds. See Bureau of Primary Health Care, HHS, at http://www.bphc.hrsa.gov/programs/CHCPrograminfo.asp; see also Public Health Service Act $\S 330,42$ U.S.C. $\S 254 b$ (2002); Social Security Act $\S$ 1905(1)(2)(B), 42 U.S.C. $\& 1396 d(1)(2)(\mathrm{B})(2001)$.
} 
community support gives community health centers a government seal of approval, but allows them to remain nonprofit, community-based organizations. This double structure, both public and private, allows them to be an excellent vehicle for the quality project linked to racial disparities. ${ }^{116}$

Payment systems are also increasingly merging the public (government) and private (employers) purchasers. Medicaid, for example, is expanding to cover people in the work force, particularly workers who have insufficient employer-based coverage. ${ }^{117}$ These purchasers, therefore, will need to work together to obtain high quality, cost-effective services from healthcare providers. Both the community health centers and the physician-led managed care organizations rely on Medicaid and Medicare funding and are closely monitored by the government agencies that supply this funding. As the coverage system, which is our primary access system, begins to merge the public and private, the regulatory framework must become more standardized and seamless. This merger facilitates incorporation of the quality/equity protocols, staffing, evaluation and monitoring. It also encourages reimbursement systems that can be calibrated to reward those organizations that provide quality care. ${ }^{118}$

Regulation is also increasingly becoming both public and private. ${ }^{19}$ An example of this convergence is the link between the public regulatory structures, such as the state Insurance Commissioner's rules, ${ }^{120}$ and the private certifying agencies such as NCQA and the Joint Commission on Accreditation of Healthcare Organizations (JCAHO). ${ }^{121}$

\footnotetext{
${ }^{116}$ MARTHA MINOW, PARTNERS, NOT RIVALS: PRIVATIZATION AND THE PUBLIC GOOD (2002).

${ }^{117}$ Barbara Zabawa, Making the Health Insurance Flexibility and Accountability (HIFA) Waiver Work Through Collaborative Governance, 13 ANNALS HEALTH L. (forthcoming Spring 2003).

${ }^{118}$ See Liz Kowalczyk, Blue Cross to Give Doctors Care-, Cost-Based Bonuses, BOSTON GLOBE, Dec. 17, 2002, at A1; Liz Kowalczyk, For Doctors, Bonuses for Quality Care, BOSTON GLOBE, Nov. 7, 2002, at A1; Bonuses for Better Care, BOSTON GLOBE, Nov. 14, 2002, at A18.

${ }^{119}$ Jody Freeman, Collaborative Governance in the Administrative State, 45 UCLA L. REV. 1, 21-22 (1997).

${ }^{120}$ See, e.g., WIS. ADMIN. CODE $\S 9.40(1)(a), 9.40(5)$ (2002).

${ }^{121}$ Joint Commission on Accreditation of Healthcare Organizations (JCAHO) is an independent, not-for-profit organization that has developed professionally based standards and evaluates the compliance of healthcare organizations against these benchmarks. It accredits over 17,000 healthcare organizations and programs in the U.S. JCAHO accreditation is used as a substitute for federal certification surveys for Medicare and Medicaid and fulfills licensing requirements in many states. See JCAHO, at http://www.jcaho.org (official commission website) (last visited Mar. 10, 2003). NCQA evaluates healthcare through accreditation, HEDIS and through a comprehensive member satisfaction survey. See NCQA, supra note 90. More than half of the nation's HMOs participate in NCQA's accreditation and certification programs and almost ninety percent of all health plans measure their performance with HEDIS.
} 
Quality standards, for example, which are now embedded in the rules issued under the patients' rights legislation, are incorporated by reference from NCQA standards. ${ }^{122}$ These standards were developed by a private, nonprofit organization but are now enforced through state mandates. The physician-led managed care organizations rely extensively on NCQA standards to create and monitor their local service performance. Emerging links between the public and private have also increased the influence on regulation exerted by disease advocacy groups, such as the American Diabetes Association, the American Heart Association, the American Lung Association and the American Cancer Society. These groups endorse protocols for care management. Obtaining these endorsements is crucial to the success of a disease management program. ${ }^{123}$ These private bodies, therefore, have become part of the public governance framework.

\section{DIFFUSING THE REDESIGNED FRAMEWORK: ACTORS, ARENAS AND ADVOCATES}

Reformers now have the opportunity to publicize the success of programs that emphasize quality and equity and to use these governance initiatives as a template. States and local communities are in the forefront of healthcare policy development and are seeking innovations that are both quality-based and cost-effective. An upsurge of concern over increasing costs of healthcare and the fiscal crises of state governments may prompt a willingness to undertake a broad look once more at the design and governance of healthcare.

\section{Participating Actors}

With healthcare reform now focused on the state and local levels, identification of the actors involved in the reexamination of healthcare governance is useful. Two new sets of actors are now becoming visible: "clinical professionals" working in teams at reformist institutions to provide care and multidisciplinary physicians taking on executive positions. The emerging delivery system also precipitated a shift in the influence and alliances of traditional stakeholders, as illustrated by the exemplary projects at reformist institutions. Consumers (patients)

Id. For additional information on NCQA accreditation, see supra note 90 and accompanying text.

${ }^{122}$ For example, in Wisconsin the NCQA standards are incorporated at WIS. STAT. $A N N$. $\&$ 609.32 (West Supp. 2002).

${ }^{123}$ Lynn Staff Interview, supra note 53; Holyoke Staff Interview, supra note 53; Richard Bohmer, E[2]M Health Services (Harvard Business School Case Study), Feb. 28, 2000 (on file with author). 
increasingly are being encouraged to assume a more active role in their healthcare. Moreover, those who pay for healthcare coverage, the government and employers, are enjoying more leverage. Their participation is essential in redesigning the delivery system.

\section{Clinical Professionals at Reformist Institutions}

New knowledge about outcomes in disease management created incentives for institutions to develop a "team" approach. By working in a non-hierarchical fashion and deeming all members of the team to be "clinical professionals," these new teams of nurses, physician assistants, community outreach workers, quality managers and physicians create better outcomes by working together rather than individually. ${ }^{124}$ They are able to achieve these outcomes more efficiently by viewing themselves as consensus-based decision-makers and scientifically-based professionals. As one medical director said of the approach to patient care at his reformist institution, "we are a team sport, not an individual sport." ${ }^{125}$

Well-run and well-managed reformist institutions like community health centers and physician-led managed care organizations are bolstered by this new team approach. The improved outcomes produced by the empowered "clinical professionals" enable their home institutions to serve as viable alternatives to the competing bureaucratic/corporate model. These reformist institutions are enthusiastic about creating a new integrated system and do not long to return to the old medical cottage industry model. ${ }^{126}$

\section{Physician-Executives}

The second group of new actors to emerge is physician-executives who endorse the concept that quality care will lead to cost savings and, more importantly, that the tools to achieve quality are already in place. The managed care revolution of the 1980s was, in large part, directed by businesspeople who thought that traditional business management would reduce healthcare costs. The result for patients and physicians was mixed and led to a heightened sense of frustration among both groups of actors. In response, some concerned physicians have taken the initiative and educated themselves in order to take on the management and leadership of healthcare institutions. ${ }^{127}$

\footnotetext{
${ }^{124}$ COMM. ON QUALITY HEALTH CARE, IOM, supra note 45, at 130-33.

${ }^{125}$ Telephone Interview with Ron Harms, supra note 85.

${ }^{126}$ Holyoke Staff Interview, supra note 53.
}

${ }^{127}$ See generally Carl F. Ameringer, Devolution and Distrust: Managed Care and the Resurgence of Physician Power and Authority, 5 DEPAUL J. HEALTH CARE L. 187 (2002) (discussing how physicians and their professional associations are regaining some of their lost 
Interestingly, the collaborative practice model and patient-centered care have returned some control of healthcare back to physicians. Disease management is founded on clinical leadership and expertise and, as such, increases the importance of physicians (and other healthcare professionals) in leadership positions. Physician leaders have enthusiastically adopted disease management approaches and, with this widespread acceptance, physician executives have been empowered. They are confident that their professional medical values and knowledge, combined with their newly acquired business skills, will allow them to more effectively control the development of the healthcare system. With physicians assuming executive leadership positions, the traditional values of medical professional ethics and autonomy are being reasserted. ${ }^{128}$

\section{Empowered and Active Patients}

Consumers assuming an active role in their own care are an integral part of the emerging healthcare system design. The necessity for consumers to understand the healthcare system, not only by managing their own diseases but also by demanding usable information about the outcomes of their care, is essential.

As evidenced by the Health Disparities Collaboratives, patient self-management has become increasingly important as an element of quality and cost control. Education and involvement of patients at the clinical level is an important component of improving patient outcomes and attaining cost-effective quality. ${ }^{129}$

For a patient to be willing to self-manage her disease, a welldesigned system must, to the extent possible, minimize the negative factors that make taking on this responsibility difficult. In general, feelings of other priorities being more important than following the disease management plan and feelings of inability to self-manage will reduce compliance. ${ }^{130}$ Drug side effects, multiple daily dosages, out-ofpocket medication costs, transportation costs and inconvenient appointment times can also lead to noncompliance with a disease management plan. ${ }^{131}$ The failure of the patient to perceive benefit in the short term or the false belief that benefit will accrue in the long term, even if they do not follow the protocol, can also lead to noncompliance. $^{132}$ When elements of care and self-management are

political clout and economic leverage).

${ }^{128}$ See id. at 193-96 (outlining the current revitalization of medical ethics).

${ }^{129}$ See Disease Mgmt. Ass'n of America, supra note 44.

${ }^{130}$ Gerber \& Stewart, supra note 41 , at 48.

${ }^{131}$ Id.

${ }^{132} I d$. 
broken down into smaller increments that the patient can understand and handle, patients are able to assume more responsibility in maintaining their health status. ${ }^{13:}$

Patients also increasingly play a larger role in the design of the general structure of the system. In community health centers, for example, the patients and community members are on the Board of Directors and are an integral part of the outcome and accountability system. Making data on outcomes available is also a way of allowing consumers to be involved in the healthcare system. ${ }^{134}$

\section{Realistic Payors}

Healthcare coverage in the United States is paid for primarily by two sets of payors: the government and employers. Both groups believe they are expending an excessive portion of their revenues on healthcare under the current system. Employers are chastened because their leadership in producing the model of managed care in the 1980s failed to curb cost escalation. Government actors control their costs, in part, by keeping their reimbursement rates low and shifting the increase in costs on to employers and healthcare providers. Government payors, however, are deeply concerned about the rising number of uninsured and the political fallout from dissatisfied voters. They, therefore, are interested in demonstrable quality measures that reduce costs, particularly if these measures can reduce racial and socioeconomic inequalities. Employers are also educated in the belief that quality can reduce costs. ${ }^{135}$

These payors have the influence and the desire to reduce cost escalation. They now realize that more allies are needed to develop and implement a new healthcare system design. ${ }^{136}$. The failures of managed

${ }^{133}$ Lynn Staff Interview, supra note 53.

${ }^{134} \mathrm{~A}$ proposed alternative role for consumers is the "consumer driven" model. In this model, financial incentives play a larger role in the patient's self-management with the patient sharing costs through high deductibles and co-payments. See Regina E. Herzlinger, Let's Put Consumers in Charge of Health Care, 80 HARV. BUS. R. 44 (2002). In response to this proposal, one physician leader points out that placing costs on the consumer could lead to poor policy decisions and could be a tremendous political disaster for the healthcare system. Telephone Interview with Ron Harms, supra note 85 . He believes this potential negative effect is' one motivation for physicians to support the quality approach for cost containment. Id. The negative effect is especially relevant for equity because minority groups are disproportionately lower-income and will be more affected by the consumer-driven approach.

${ }^{135}$ See, e.g., Peter T. Kilborn, Ambitious Effort to Cut Mistakes in U.S. Hospitals, N.Y. TIMES, Dec. 26, 1999, at $\S 1$, at 1 .

${ }^{136}$ For example, The Leapfrog Group, a consortium of healthcare payors, focused on using its purchasing power to increase quality in healthcare, has recently begun partnering with non-payor healthcare entities such as JCAHO in an attempt to increase its ability to effect change. JCAHO Becomes Formal Partner With the Leapfrog Group, U.S. Newswire, Jan. 16, 2002, available at 2002 WL 4573378. 
care can be accounted for, in part, by insufficient communications early on with healthcare professionals and consumers. The payors have learned from this mistake.

\section{Arenas}

The escalation of healthcare costs is the momentum behind redesigning the healthcare framework. States are confronting the "perfect storm" in budget shortfalls due to a decline in revenue, increased numbers of uninsured and escalating Medicaid costs. ${ }^{137}$ Employers are also pushing for action in the face of increased premium rates and stalled profits. ${ }^{138}$ This cost-based momentum has the ability to effect actual change: there are alternative models of care available and actors who are knowledgeable about the potential for change and are eager to achieve it. These actors have a variety of tools available to them, including private standard setting systems, protocols on quality developed by clinical organizations, consumer information, equity guidelines and successful programs to reduce disparities.

Without leadership and alliances that work on multiple levels, the framework cannot be diffused. Whoever takes the leadership role in the redesign process must form alliances with other interested stakeholders. These alliances will be necessary regardless of the level at which the leadership emerges. The only way the necessary reforms will be undertaken is through a policy network initiative where all stakeholders come to the table.

Recently, states have exerted exceptional influence in shaping policies for programs such as welfare and expanded healthcare coverage for uninsured children. ${ }^{139}$ In the wake of the federal government's seeming inability to implement healthcare reform, as demonstrated by the failure of the Clinton health plan, local and state public and private agencies may continue to take a greater role in healthcare delivery and design. ${ }^{140}$ As such, they may take the lead in forming the alliances for embedding the framework under the rubric of cost containment. ${ }^{141}$ States can use the local experimentation

\footnotetext{
${ }^{137}$ Robert Pear \& Robin Toner, Amid Fiscal Crisis, Medicaid is Facing Cuts From States, N.Y. TIMES, Jan. 14, 2002, at A1.

${ }^{138}$ Reed Abelson, Hard Decisions for Employers as Costs Soar in Health Care, N.Y. TIMES, Apr. 18, 2002, at C1.

${ }_{139}$ Robert Pear, Democratic Governors Seek U.S. Aid, N.Y. TIMES, Dec. 8, 2002, § 1, at 39.

${ }^{140}$ Health policy scholars examining quality governance have also endorsed states as the initial arenas for embedding the quality approach. See TROYEN A. BRENNAN \& DONALD M. BERWICK, NEW RULES: REGULATION, MARKETS, AND THE QUALITY OF AMERICAN HEALTH CARE (1996).

${ }^{141}$ Local and state agencies and governments may be more receptive to the medical establishment because healthcare costs make up a substantial part of their budgets and because
} 
demonstrated in the Health Disparities Collaboratives and the physician-led managed care organizations in developing their qualitybased delivery systems. This merger of local experience and state monitoring and funding can be a productive governance approach. ${ }^{142}$ For health disparities, for example, local action may have the advantage of addressing minority populations that are sometimes neglected in state policy-making.

Initiatives currently under consideration in Wisconsin provide an example of a potential state-based quality approach to cost containment. Facing the "perfect storm" scenario, legislative hearings were held in Madison in 2002 on how to resolve healthcare cost escalation. ${ }^{143}$ An impressive number of groups that testified indicated that any cost containment initiative must be tied to quality measures. ${ }^{144}$ The speakers, representing HMOs, commercial insurers, hospitals, consumer groups, labor unions, employers and healthcare professionals, pointed out again and again that quality was the best way to decrease costs. $^{145}$ In particular, they emphasized the disease management approach. ${ }^{146}$

The Wisconsin AFL-CIO put forth the most comprehensive proposal. ${ }^{147}$ It proposed a universal plan for the state that would merge the public and private health financing systems. Among the central themes of the proposal was the importance of quality in this new system. The AFL-CIO stated that quality is essential because it would both curb costs and produce an accessible, universal and equitable system. The plan was also remarkable because it presented a statebased approach to universal coverage and quality, an approach not usually associated with organized labor. ${ }^{148}$

Another response to the 2002 hearings is the Wisconsin Hospital Association's (WHA) Quality Accountability Initiative. The state-wide hospital trade association developed this initiative, which focuses on

the medical industry represents a powerful constituency. See Ameringer, supra note 127.

${ }^{142}$ See generally David J. Barron, A Localist Critique of the New Federalism, 51 DUKE L.J. 377 (2001).

${ }^{143}$ Joe Manning, Legislators Target Health Care; Two Public Hearings This Summer Will Look at Costs, MILWAUKEE J. SENTINEL, June 1, 2002, at 1D.

${ }^{144}$ Joe Manning, Testimony on Health Care Costs; Lawmakers Hear from Experts, and the News Isn't Good, MILWAUKEE J. SENTINEL, July 17, 2002, at ID.

${ }^{145}$ See Manning, supra note 143; see also Manning, supra note 144.

${ }^{146}$ Julie Sneider, Treating a Long-Term Cost Problem, BUS. J. SERVING GREATER MILWAUKEE, Sept. 13, 2002, available at http://milwaukee.bizjournals.com/milwaukee/stories/2002/09/16/focus2.html.

${ }^{147}$ Matt Pommer, AFL-CIO Proposes Unified Care Plan, CAPITAL TIMES, Aug. 13, 2002, at 1A; Phill Trewyn, AFL-CIO Health Plan Gains Steam, BUS. J. SERVING GREATER MILWAUKEE, Oct. 11, 2002, available at http://milwaukee.bizjournals.com/milwaukee/stories/2002/10/14/story 1.html.

${ }^{148}$ Pommer, supra note 147; Trewyn, supra note 147. 
creating standards for hospital quality, gathering data on each hospital, comparing this data to the standards and sharing the results with the public. WHA released the plans for this initiative in December 2002 and is currently seeking the support of other stakeholders in the state. ${ }^{149}$

There is, however, skepticism about a local and state-based approach. The role of the federal government remains crucial: providing funding, creating standards for performance and monitoring and publicizing the results of benchmarking. The Health Disparities Collaboratives demonstrates how this role for the federal government is necessary for an effective quality-based approach. Some scholars are proposing an information and disclosure model for federal government regulation of healthcare that has some similarities to the Health Care Disparities Collaboratives model. The Securities and Exchange Commission (SEC) has been suggested as a conceptual paradigm for a federal oversight role that is less intrusive than the more traditional command and control oversight mechanisms. ${ }^{150}$

\section{New Advocates in New Roles}

A redesigned system does not automatically ensure quality and equity in healthcare. The lawyers and healthcare professionals who fought to eliminate segregation in healthcare understood that the voices of the poor and disadvantaged must be heard. Advocates in the new system must recognize the same. In order to monitor the system, there should be transparency. Useful data measures that demonstrate the results of the quality system can be made available to the public. Public production of data is always a struggle and advocates need to ensure that the public can evaluate the results of data gathering. Patients, and other participants in the system, must be able to speak out if the redesigned system does not work for them without being labeled "troublemakers." Without this feedback, the system will atrophy and decline. Using their own legitimacy, advocates can support the participation of patients in this feedback loop. ${ }^{151}$ Finally, the redesigned system is based, to a great extent, on guidelines and benchmarking often developed by private organizations. Advocates can participate in

\footnotetext{
${ }^{149}$ Press Release, Wisconsin Hosp. Ass'n, Hospital Association Will Collect, Share Hospital Quality, Safety Information (Dec. 18, 2002), available at http://www.wha.org/newsCenter/news_releases.aspx.

${ }^{150}$ See William M. Sage, Accountability Through Information: What the Health Care Industry Can Learn from Securities Regulation, Milbank Mem'l Fund (Nov. 2000), at http://www.milbank.org/reports/0012sage.html.

${ }^{151}$ William Sage argues that physicians should not serve as advocates because of their inherent conflicts of interest. Sage believes advocacy in the healthcare context should be left to lawyers. See William M. Sage, Physicians as Advocates, 35 HOUS. L. REV. 1529 (1999).
} 
the development of these accountability measures to ensure that these measures reflect the experiences and needs of racial and ethnic minorities.

The methods to achieve the participation of the poor and disadvantaged will be different in the emerging system. Rather than relying on civil rights lawsuits or commenting on federal agency rulemaking, these new advocates will need to participate in reformist institutions, join public-private collaborations. and monitor the outcomes of the healthcare delivery system. In order to play this role, the advocates need to acquire expanded knowledge, practice in varied sites and arenas, and understand the diverse role of law. With training, insights and a place to practice, physicians, lawyers, nurses, community workers and patients can serve as advocates. ${ }^{152}$

Acquiring the requisite amount of expanded knowledge is a daunting task for the new advocates. They need to obtain an understanding of how community and professional attitudes and cultural norms affect healthcare services, as well as how environmental and social factors, such as housing conditions and the lack of nutritious food in a community, affect the health of people in the community. The linking of private organizations and public systems requires knowledge of both public administration and business entrepreneurship. Successful advocates must also incorporate evidence-based medicine into the design of healthcare institutions and systems. Finally, they will need to understand how technology can assist in the monitoring and evaluation of healthcare.

Already there are reformists working within law schools and health professional training institutions to modify the existing curricula to provide this expanded knowledge and training. ${ }^{153}$ An emphasis on multi-disciplinary programs is necessary as curricula are re-envisioned. For those already engaged in professional practice, shorter courses exist to impart new knowledge and provide hands-on experience. ${ }^{154}$

The expanded knowledge is attainable not only through the availability of improved educational institutions, but also in new practice sites and arenas. By getting out of the independent law office and the customary physician practice, advocates can redefine their professional roles by practicing in a non-traditional environment.

\footnotetext{
${ }^{152}$ Cf. id.

${ }^{153}$ See, e.g., Anne Barnard, Radical Change in Doctor Training Urged, BOSTON GLOBE, Dec. 8, 2002, at A1; Trubek \& Farnham, supra note 98, at 257.

${ }^{154}$ For example, the American College of Physician Executives offers short courses for physicians on a wide variety of topics related to management and leadership. Am. Coll. of Physician Executives, List of Courses, at http://www.acpe.org/Education/courses/index.htm (last visited Mar. 10, 2003).
} 
Community health centers, for example, are being redesigned to emphasize the team approach and patient self-management. Multidisciplinary legal practices are also examples of how a re-imagined practice site can encourage and create new knowledge and redefine professionals. The increased use of collaborative learning networks will also create new arenas in which advocates can participate in designing and monitoring the system.

Finally, advocates must understand the variety of ways in which law can be used to achieve an equitable healthcare system. Outcomes data, benchmarking and the release of public information, for example, are new ways of measuring behavior, obtaining sanctions and providing transparency. Norms created by private institutions, such as JCAHO and NCQA, can also be effective tools in achieving accountability. Using these new instruments and procedures, transparent law can be achieved without traditional regulation. ${ }^{155}$

\section{CONCLUSION}

Lawyers and healthcare professionals have been working together over a number of years to achieve an equitable healthcare system. From the beginning, their shared knowledge has been crucial in envisioning and implementing changes within the system. As healthcare moves toward an indirect quality approach to achieving equity, advocates must remain vigilant. The emerging system provides a hopeful scenario for the future. As this system continues to develop, advocates must ensure that racial and ethnic inequalities are actually being reduced.

${ }^{135}$ These guidelines, recommendations, policy suggestions and other government systems designed to influence behavior without imposing formal legal obligations are known as "soft law" or "new rules." See Trubek, supra note 100, at 600; BRENNAN \& BERWICK, supra note 140. 
